\title{
Historia de la sal en el Ecuador Precolombino y Colonial
}

Ernesto Salazar ${ }^{1}$

\section{RESUMEN}

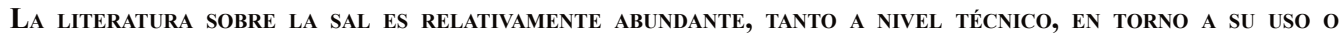
EXPLOTACión, COMO A NIVEL CULTURAL Y SIMBólico, EN CUANTO a SU CONSUMO. El ECUADOR TIENE MUY POCa LITERATURA AL RESPECTO, Y EL AUTOR HA ESTIMADO ÚTIL OFRECER UNA VISIÓN GENERAL DEL TEMA, UTILIZANDO FUENTES BIBLIOGRÁFICAS DESPERDIGADAS EN LA DOCUMENTACIÓN HISTÓRICA. QUEDA CLARO QUE ARQUEOLÓGICAMENTE NO HAY EVIDENCIA ALGUNA DE CONSUMO Y EXPLOTACIÓN DE SAL, AUNQUE LA LITERATURA COLONIAL TEMPRANA DA unos poquísimos datos que pUeden Ser extrapolados al Pasado precolombino. EN todo Caso, el lector PODRÁ APRECIAR EN LA LITERATURA TARDÍA LA IMPORTANCIA QUE ADQUIERE EL MINERAL PARA LOS PUEBLOS INDÍGENAS DEL PAÍS, QUE CONFORMAN ASENTAMIENTOS MULTIÉTNICOS EN LAS FUENTES NATURALES, ESFERAS DE COMERCIO, Y UN APEGO A LA SAL PARA EL ACCESO A LA "CIVILIZACIÓN".

Palabras claves: Sal, Fuentes naturales, Explotación, Intercambio, Civilización.

\section{Abstract}

The SALT'S Literature is RELATIVELY ABUNDANT, IN BOTH ORDERS: TECHNICAL (IT'S USE OR OPERATION) AND CULTURAL - SYMBOLIC (CONSUMPTION). ECUADOR'S LITERATURE PRODUCTION ABOUT THIS MATTER IS VERY LITTLE, AND SO, THE AUTHOR HAS ESTIMATED USEFUL TO OFFER AN OVERVIEW OF THE ITEM, USING SCATTERED BIBLIOGRAPHIC SOURCES FOUND IN THE HISTORICAL RECORD. CLEARLY, THERE IS NO ARCHEOLOGICAL EVIDENCE OF CONSUMPTION AND EXPLOITATION OF SALT, BUT THE EARLY COLONIAL LITERATURE GIVES SOME DATA THAT COULD BE EXTRAPOLATED TO THE EARLY COLUMBIAN PAST. IN ANY CASE, THE READER CAN APPRECIATE THE IMPORTANCE THAT THE MINERAL TOOK FOR THE INDIGENOUS PEOPLE OF THE COUNTRY, WHOM SET SETTLEMENTS AROUND THE NATURAL RESOURCES, TRADE AREAS AND THE RELIANCE IN SALT AS A “CIVILIZATION" FACTOR.

Key words: Salt, Natural Resources, Exploitation, Trade, Civilization. 


\section{Introducción}

omando como punto de partida la necesidad biológica de la sal, el autor revisa los
registros arqueológico y etnográfico del Ecuador, en busca de información sobre su
explotación y consumo. La información disponible permite especular sobre el uso tardío del mineral en tiempos precolombinos, con intercambio relativamente reducido. En la Colonia, y ante la demanda del mineral por parte de los colonizadores europeos, se desarrolla un abierto comercio que, a la postre, determinará el uso generalizado de la sal entre los grupos indígenas serranos, ya sea a partir de fuentes minerales locales, o de la sal marina costera. Los grupos de selva tropical, tradicionalmente más reticentes a su uso, acabarían también recurriendo a la sal por influencia de los misioneros. Sin embargo, el aprovisionamiento de este recurso se constituirá en la operación más larga y difícil de su quehacer cotidiano, particularmente por la lejanía de las fuentes naturales. A nivel simbólico, la sal representaría una de las interfaces entre la civilización y el salvajismo, y un indicador claro de status en la sociedad indígena.

La información disponible sobre las fuentes de sal y su explotación en el Ecuador es de naturaleza diversa. Las crónicas dan alguna información, pero de carácter general que no permite la construcción de contextos adecuados para la situación del país. Datos más específicos, pero demasiado puntuales, se encuentran en las Relaciones Geográficas de Indias (Jiménez de la Espada, 1965) en las que constan 39 de pueblos del Ecuador; y las Relaciones HistóricoGeográficas de la Audiencia de Quito (Ponce Leiva, 1992-94), que cubren el territorio del actual Ecuador con mayor amplitud que los textos de Jiménez de la Espada. La consulta en el Archivo Nacional de Quito no ha sido muy fructífera; apenas un par de casos referentes a explotación de salitre para la producción de pólvora, y ausencia total de pagos de tributos en sal (aunque estos se mencionan en algunas "relaciones" publicadas). Por último, cabe citar los relatos de viajeros y misioneros, que acaso por ser consumidores constantes del mineral, son más proclives a consignar datos sobre la sal y su consumo.

\section{De sales y tradiciones}

El cloruro de sodio, o sal, es un mineral de variadísima utilización y no sorprende que haya sido objeto de intensa comercialización. Sin contar con la moderna utilización, en la ganadería y la industria química, los usos tradicionales de la sal se refieren a la salud y dietas humanas, la preservación de los alimentos, la farmacopea y la actividad ritual. Se ha estimado que, entre los humanos, los cazadores recolectores necesitan diariamente un mínimo de 2.5 gr. de sal por día, y los agricultores que consumen cereales, un mínimo de 5 gr. (Ewald, 1985: 7). Un maya precolombino (i.e. habitante de clima tropical) habría requerido de 8 a 10 gr. diarios, y hasta 30 gr., si estaba trabajando en el campo, y una ciudad como Tikal (45.000 habitantes, en el periodo Clásico Tardío), un total de 131.4 toneladas por año (Andrews, 1983:9-10). Si estos datos son ya suficientes para inferir la gran cantidad de sal que debe ser producida solamente para fines biológicos, los otros usos de la sal multiplican exponencialmente la cantidad básica necesaria para la vida cotidiana.

En estado natural, la sal se encuentra en formación rocosa, de allí su nombre de sal de roca o de sal gema. No se conoce un afloramiento natural de este tipo en Ecuador; pero en la Colonia se traía al país una excelente sal de los varios afloramientos que existían en el Gran Pajonal de Perú, en torno al cerro de Chanchamayo o Cerro de la Sal. Según Fray Manuel Biedma (1989:102),

"Es el Cerro de la Sal un cerro, no de los mayores, a manera de loma que cría y produce a manera de mina un género de sal colorada en piedra, que a veces sale tan maciza y pura que generalmente 
parece piedra, sin mezcla de tierra alguna; es muy sabrosa y sala mucho, y es la que más estiman los indios de adentro... [selva baja]".

Esta sal fue por mucho tiempo monopolio de los indios campas, a quienes acudían los indios forasteros es pos de autorización para explotar los afloramientos, previo un "pago" en especies como plumas, loros, y otros productos selváticos. Comerciantes de larga distancia, como los indios de los ríos Napo y Putumayo, acudían al lugar que, poco a poco, se fue internacionalizando con la presencia de varios grupos étnicos que hacían sus labores sin hostilidad alguna (Rydén, 1962).

Las demás sales conocidas deben ser extraídas por medio de la evaporación del agua. La sal marina, la más cotizada, requiere la construcción de piscinas de poca profundidad cubiertas de agua de mar que, al calor del sol, se evapora y deja el mineral en el fondo. Hay también sales de manantial o arroyos salados, que requieren la ebullición del agua en recipientes para obtenerlas. En el Ecuador, los términos salado, salina, saladero, o sus equivalentes quichuas como cachihuayco, cachiyacu, usados como topónimos, son muy sugerentes al momento de buscar fuentes del mineral.

Existen también muchos terrenos salados o salitrales que dan sales de mala calidad (siempre algo amargas y sucias) y que deben ser excavados para obtener la tierra salada, la misma que con acopio de agua puede liberar la sal por evaporación o ebullición. En la Colonia se ha reportado el uso y explotación de varios salitrales, ubicados sobre todo en la sierra.

Finalmente, hay una sal "vegetal", que se obtiene de plantas aciduladas, por medio del mismo proceso de ebullición. Patiño (1992:35ss) cita para la América equinoccial una docena de plantas utilizadas, entre las que sobresalen las palmas, como Iriartea ventricosa y Bactris gasipaes. Los misioneros franciscanos del Caquetá colombiano señalaban, en 1773, que los indios Huaques daban gusto a sus comidas con "el salitre intenso de la mata quemada que llaman huajary, que remeda la sal de que carecen" (en Zawadzky, 1947:209). En fin, según Palacios y Zoffoli (1991:299) los Guaraníes de las reducciones jesuíticas del Rio de La Plata tenían una habilidad reconocida en aprovisionarse de plantas que contenían sales naturales. Aunque esta sal es de explotación muy limitada por su sabor amargo, ha servido alguna vez como ítem de intercambio. Por ejemplo, Useche Losada (1989:188) la menciona entre los productos de intercambio del sistema orinoquense. Heriarte (en Patiño, 1992:37) también reporta que los Omaguas cuajaban la ceniza de la planta capimassu en panes que eran objeto de comercio.

El uso tradicional de la sal comprendía básicamente la preservación y preparación de alimentos, la farmacopea y la actividad ritual. La preservación de alimentos tiene larga data en la historia humana. Por cierto, el asoleado simple (exposición al sol) y el ahumado de la carne y el pescado precedieron, sin duda, a la salazón, en las técnicas de preservación. Wheat (1972:111ss), al ponderar sobre la preservación de la carne de los 200 bisontes matados en el sitio paleoindio de Olsen-Chubbuck (Wyoming), recurre a la etnografía de los indios de las Grandes Llanuras: todos los grupos mencionados allí asoleaban la carne o la secaban cerca de fogatas, sin recurrir a la sal. Olivas Weston (2006:112) consigna igual aseveración en el caso de los pueblos precolombinos de los Andes. En Ecuador, no hay noticias a este respecto, pero se sabe que, desde tiempos coloniales, se ha practicado el asoleo y ahumado de carnes pero con sal para facilitar la deshidratación y ahuyentar los insectos. En algunos pueblos que no tienen electricidad es todavía posible ver perchas con lonjas de carne [“charqui"] secándose al sol.

Otro asunto es el uso del mineral para salar comidas y darles buen gusto. Como observación general, Cobo (1964, 2: 21) señala que los indios americanos "no son nada limpios en guisar y preparar sus manjares; conténtanse los más regalados con comerlos medio crudos o mal asados o medio cocidos con no más recaudo que agua y sal y algunas herbezuelas, sin reparar mucho en lavarlas antes". En Mesoamérica, el área maya ha dado abundante información arqueológica sobre la producción y el intercambio de sal, en tiempos precolombinos. Sin embargo, no se ha conservado evidencia alguna sobre su uso en la culinaria. En cambio, en el área azteca hay 
algunas noticias escuetas pero dignas de mencionarse. Un documento sobre los tributos de varias ciudades aztecas, citado por Prescott (s.f.:28), señala entre otras cosas "2000 panes de sal muy blanca, refinada en forma de molde, para el consumo solamente de los señores de México". En otro documento, reportado por Torquemada (en Prescott s.f.:101) sobre los gastos anuales de palacio, se consignan 1300 canastas de sal. En fin, en la larga guerra (50 años) de los mejicanos con los señores de Tlaxcala, el bloqueo económico de los mejicanos fue tal, que los Tlaxcalas se quedaron sin recursos estratégicos como el algodón, el cacao y la sal. Sin embargo, en los tiempos de tregua, los mejicanos enviaban secretamente regalos de estos productos a los señores de Tlaxcala. Prescott (s.f.:225) señala que con tanta abstinencia, los tlaxcalas tenían problemas en reajustarse al uso de la sal en sus comidas.

En los Andes, hay información sobre la culinaria inca. Cobo $(1964,1: 113)$ indica que los indios gastaban muy poca sal "porque tenían pocas cosas en qué echarla...pues hasta la cecina que hacían y pescado que secaban... era sin grano de sal". En todo caso, sus comidas las sazonaban con sal, aunque de una manera singular: no se ponía sal en la comida, sino un terrón grande junto al plato, lamiéndolo frecuentemente para dar más sabor al paladar que al guisado. Incluso, cuando los comensales eran muchos, y había solo un terrón, éste iba de lengua en lengua, para la consiguiente lamida de cada comensal. El consumo de sal iba siempre acompañado de ají. En una versión algo modificada de esta costumbre andina, Juan y Ulloa $(1748,1: 565)$ reportan, para los indios de Quito, que

\footnotetext{
"usan mucho la sal con ají: escogen los terrones gruesos de esta, y muerden un bocado de ella, y otro de ají; y después la mashca o camcha [tostado]; en cuya forma alternan de todo hasta que quedan satisfechos. Son tan apasionados por la sal en este método de comerla, que estiman uno o dos terrones grandes, más que cualquier otro manjar, y se les conoce la inclinación a ella en el cuidado, con que luego que ven sal, van a buscar los terrones, y guardarlos".
}

Las comidas cotidianas eran frecuentemente interrumpidas con días de ayuno, en los cuales los indios se abstenían de consumir sal y ají, incluyendo a veces carne, chicha y hasta encuentros sexuales en ayunos rigurosos (Olivas Weston 2006:29).

La farmacopea de la sal es variada y pintoresca. En el Perú, Valdizán y Maldonado (1985, $2: 13)$ señalan entre los usos de la sal "de cocina" los siguientes: granos de sal en las muelas cariadas, como analgésico; disueltos en orina humana reciente para limpiar heridas; puestos en la boca para producir salivación; pulverizados con agua para la jaqueca y el catarro, etc. En Ecuador, en cambio, su utilización es casi nula en la medicina tradicional. Más aún, fuentes generales, como la Medicina aborigen de Estrella (1977) y el Diccionario del folklore ecuatoriano de Carvalho-Neto (2001), no hacen referencias a la sal.

El uso de la sal en ritos religiosos precolombinos es menos conocido. Se conoce que los aztecas tenía una diosa de los salineros, Uixtociuatl, a quien se le ofrecía incluso víctimas humanas (Ewald 1985:10). En el Perú, la relevancia del mineral era acaso menor. Cristóbal de Molina (1989:111) menciona que en la batalla ritual de Anan Cuzco y Hurin Cuzco, en diciembre, los guerreros comían con sal, de la que, a su vez, se habían abstenido en las ceremonias de armadura como caballeros. Asimismo, señala que, en la fiesta del sacrificio, Moyucati, también en diciembre, había corredores que seguían las ofrendas que bajaban por el río Capimayo, desde el Cuzco hasta Ollantaytambo. A su regreso, los cuzqueños podían apreciar el esfuerzo realizado, ya que los corredores venían "trayendo en sus manos, los que más habian corrido, una lanza hecha de sal y otros halcones de sal; y los postreros y que menos habian corrido unos sapos de sal [lo que] fue causa de hacer burla de ellos" (Molina 1989:117).

Estas instancias, sin embargo, poco dicen de la simbología de la sal entre los antiguos peruanos. Por cierto, en el largo listado, que proporciona Cobo (1964,2:169ss.), de las guacas y adoratorios que formaban los ceques del Cuzco (entre los cuales a menudo se citan cerros, piedras y canteras), no se ha encontrado un solo depósito de sal que haya constituido guaca del 
imperio. Igual cosa se puede decir de las guacas citadas por Albornoz (1989:187ss.), entre las cuales se mencionan algunas del territorio del actual Ecuador.

En las tierras bajas, sin embargo, se han detectado instancias de fuerte simbolismo de la sal. Por ejemplo, Hugh-Jones (1979:195) y Echeverri (2000) han destacado el carácter espermático de la sal en la explicación de la sexualidad en los indios del río Vaupés, y los huitotos de Colombia, respectivamente. Otro caso interesante de construcción simbólica, en este caso en torno al intercambio de sal, viene de los campas en cuyo territorio se encontraba el famoso Cerro de la Sal, ya mencionado. Según Varese (1973: 88ss), entre los Campa, el intercambio de sal sobrepasaba la esfera económica o social, adquiriendo con otros productos ribetes de "comercio sagrado". En la mitología campa, la sal es uno de los bienes que posee Pachakamaite, el dios bueno que provee casi de todo a los Campa. El "ayúmpari" es el comerciante de lo sagrado. Especie de pochteca mexicano o mindalá yumbo, el ayumpari recorre las selvas llevando diversos productos de intercambio, entre ellos la sal de Pachakamaite. La circulación de los bienes está expresada en el mito campa por una especie de jornada iniciática que realiza el ayúmpari hasta la morada de Pachakamaite para obtener del dios los productos a ser distribuidos. Numerosas pruebas debe pasar el comerciante, entre ellas el encuentro con los chori o viracochas (comerciantes mestizos) que en vez de entregar a los Campas los productos obtenidos de Pachakamaite, prefieren venderlos, en lugar de darlos en trueque como hace el ayúmpari (Varese 1973:311).

\section{La sal de la Costa}

Una de las primeras noticias sobre el uso prehispánico de la sal, proviene de la visita de los españoles al pueblo de Tacamez (Atacames), en 1525, donde los españoles encontraron toda suerte de viandas, "no faltando la sal", como señala Cieza de León (2001:69) en la Tercera Parte de la Crónica del Perú. Frases similares se cuelan, ocasionalmente, en los documentos, en referencia al pasado precolombino, como aquella de Requena (1982:69) de que la sal ha sido llevada a la Sierra "desde el tiempo de los indios".

Importante información sobre la explotación y comercio de la sal en la Colonia se encuentra en varios documentos, particularmente los de Montúfar Fraso (1994), Requena (1982) y Zelaya (1994). En todos se señala la abundancia del mineral en la Costa y la participación activa de los indios en su producción y comercialización.

En la descripción de los varios partidos que comprende la provincia de Guayaquil (1774), Don Francisco Requena señala la presencia y explotación de sal en los partidos de la isla Puná y Santa Elena, con importante convergencia del mineral en el partido de Babahoyo para su comercialización. En la zona meridional de la isla de Puná habían "copiosas salinas" que, junto con el mangle, eran los únicos artículos que los isleños comerciaban con El Callao y Lima (Requena, 1982:40). En Babahoyo, pueblo del partido homónimo, se encontraban las Reales Bodegas, por donde circulaba lo que venía de la Sierra a la Costa y lo que iba de esta a aquella. Por vía de Riobamba y Guaranda bajaban paño y lienzos serranos con destino a Lima y todo el Perú, y víveres diversos para el abastecimiento costero local (harinas, dulces, azúcar, jamones, etc.). Y por la misma vía subían a la Sierra las innumerables recuas cargadas de sal (cada año más de 4000 fanegas de 18 arrobas cada una), además de cacao, arroz, algodón, aguardiente y cera locales, y también hierro, acero y ropas de Castilla (Requena, 1982:46). Aunque el aguardiente tenía mayor salida económica para los arrieros indios, el transporte era muy difícil por los impuestos y el gran peso de los contenedores (i.e. botijas de barro muy grueso), razón por la que preferían subir a la Sierra con sus mulas cargadas de sal. Además el trato de blancos y mestizos hacia los indios era humillante y fuera de control:

\footnotetext{
"Que la sal no tenga el peso que debe en cada fanega, que está mezclada la negra con la blanca, o cargada de tierra, o que el precio era excesivo, como no pueden pasarse sin sal y a el bodeguero le tiene cuenta buscar arbitrios para estancarla impidiendo a otros la venta de este género, se
} 
la admiten con las condiciones más gravosas. ¿Si la sal debe entrar en la aduana para pagar el impuesto, quién la volverá a sacar cuando quiera, teniendo mucha el administrador que vender?" (Requena 1982:47).

En el partido de Santa Elena, Requena señala la llamada Punta o Puntilla como la zona donde los barcos de Perú y de otras procedencias se abastecían de sal. Estos barcos conducían su carga todo el año a Guayaquil, para consumo local, y a la feria de Babahoyo para, consumo externo; allí se vendían no menos de cuatro a cinco mil fanegas. De ordinario se vendía mucho más la sal de La Puntilla por ser algo más blanca que la sal del Morro y de Puná. Otro destino de la sal costera era la provincia de Chocó. Muchos barcos atracaban directamente en Guayaquil para llevarse lo que más podían del mineral, por las importantes ventajas económicas que daba el comercio con Chocó.

"El modo de hacer la sal en este partido es bien simple: labran por la orilla del mar, en los parajes adonde no alcanza el embate de las olas, unos pozos (de los cuales hay al presente 60) de 5 a 6 pies de profundidad [1.50-1.80 m.] a los que filtra el agua del mar, la cual se evapora al cabo de cuatro meses la mayor parte y deja una sal marina menuda que jamás forma grandes cristalizaciones; ésta la amontonan en la playa para que acabe de secarse perfectamente. Como rara vez llueve por esta costa, hacen de cada pozo tres cosechas al año; el mal olor de esta sal y su poca solidez, que la hace susceptible en poco tiempo de la humedad, motiva a que tenga aprecio en Guayaquil para sazonar los alimentos y, para el uso de las mesas, la sal fósil que producen los valles del Perú en los minerales de Sechura. Córtanla allí en ladrillos de media vara de largo, que salen de una blancura y consistencia que los hacen apreciables; por esto reservan la de Santa Elena en esta provincia para conservar las carnes y los pescados de la pronta corrupción, y para conducirla a la sierra, adonde la llevan desde el tiempos de los indios, pues como menos común la dan más estimación" (Requena 1982:69).

El pueblo del Morro (partido de Chongón), ubicado en el continente, frente a la isla de Puná, también recogía sal, con la participación de muchos indios, ya sea en tareas de salinas o como marineros de las chatas y balsas que iban a Guayaquil. La explotación era en menor escala que en La Puntilla, acaso por su baja calidad, aunque la producción anual de 2000 fanegas reportada por Zelaya en 1765 no es nada despreciable (Zelaya 1994:364). En todo caso, se conoce que los habitantes del Morro usaban su mineral solamente para salar el abundantísimo venado que cazaban en su entorno, enviando el resto a la Sierra:

"En el pueblo del Morro se coge sal...y tienen también diferente modo de sacarla. Después que
tienen hechos los pozos, los introducen con acequias el agua del mar o de sus esteros, la que se pone
a nivel con la marea; de conformidad que como hacen a bulto las excavaciones se llenan demasiado
y tarda mucho en condensarse la sal; por esto no la sacan hasta los seis meses, y con alguna tierra
de la que arrastró a los pozos la misma agua; así sale de color oscuro, de peor calidad que la de la
Punta; pero con toda esta diferencia, por el menos valor tiene su aprecio entre los indios pobres de
la sierra" (Requena 1982:73-74).

\section{La sal de la Sierra}

En la Sierra ecuatoriana, la explotación e intercambio de la sal están ligados a varias fuentes naturales, que sirven a los pueblos de las inmediaciones. En general, los indios la consumían localmente, ya que los españoles preferían la sal marina. La fuente más septentrional es la que se encontraba en la jurisdicción del pueblo de Mira, a unas 15 leguas de Quito. Salinas Loyola (1965b:207) señala que se trata de fuentes de agua salada explotadas por indios del Capitán Luis Ango, cacique de Otavalo. Se desconoce el emplazamiento de este lugar; pero alguna relación debe tener con el pueblo de Salinas (valle del Chota no muy lejos del río Mira) que, en la Colonia temprana, florece por la explotación del mineral y la producción de ají, algodón y algo de coca 
(Caillavet, 2000:66, 72). El carácter multiétnico de la explotación de la sal es destacado por Valverde y Rodríguez (1965:177): "y todos los pueblos de esta provincia tienen allí repartido a cada uno su parte puestos indios en la labor della". En todo caso, la sal de Mira o Salinas era más bien parda y amarga, consumida casi sólo por los indígenas, en el marco de una amplia esfera comercial:

\begin{abstract}
"Hay en el distrito de mi corregimiento un pueblo ques del repartimiento de Otavalo, donde los indios que están cogen la tierra que está como salitre y la cuecen en unas ollas y hacen de ella una sal muy ruin, y desta sal hacen mucha cantidad y con ella tienen grandísima contratación los dichos indios naturales de aquel pueblo, que se la van a mercar de todos los pueblos de esta comarca, y también vienen a mercarla los indios infieles que no están conquistados..." (Paz Ponce de León 1965:239-240)
\end{abstract}

Por cierto, los españoles preferían la sal del mar que llegaba regularmente a Quito. De hecho, también los indios civilizados de Quito, comían todas sus comidas con un poco de sal (Salinas Loyola 1965b:220, 226), que era traída desde el embarcadero de Guayaquil, proveniente de la isla Puná. Montúfar y Fraso (1994:337) reporta en 1754 que de las Reales Bodegas de Yaguache salían para Quito 6.000 fanegas anuales de sal.

Una fuente de relevancia arqueológica está relacionada con Cachillacta, el pueblo de la sal, ubicado en el Noroccidente de Pichincha. Según Lippi (2004:85-86), documentos históricos tempranos han mencionado este pueblo con la explotación de alguna mina de sal de los alrededores, que habría sido explotada por los indios locales en cantidad suficiente como para haber sido comercializada con la Sierra. Lippi logró descubrir, en la selva, el antiguo asentamiento en un lugar conocido aún al presente con el nombre de Cachillacta, que justamente tiene en su cercanía algunos cursos de agua salados. No se ha descubierto mina de sal, si la hay, pero la explotación de los arroyos puede explicar la profundidad temporal (que iría hasta 1.500 B. B.), que tiene la cultura material en este lugar.

Los Puruháes de Chunchi y Alausí se abastecían de la sal costera, pero los de Chunchi iban a traerla ellos mismos del Embarcadero (Babahoyo o Bodegas), donde la trocaban por grandes cantidades de cabuya procesada, muy solicitada para los navíos que cruzaban la Mar del Sur (Paz Maldonado 1965:261, 289). En la escueta información que brinda Paz Maldonado, se destaca una abstención social (o ritual) de la sal, que merece algún comentario. En efecto, cuando caía un rayo en la casa puruhá, los ocupantes la abandonaban definitivamente, no sin privarse de sal y ají por algunos días después del suceso (Paz Maldonado, 1965:264, Ytaliano, 1965:289). Este aspecto ha sido brevemente tratado por Wörrle (1999:144) en el marco de la dicotomía fríocaliente que predomina en la culinaria y en la salud del mundo andino e hispanoamericano. Dado que la sal es, en general, un mineral "caliente", el comportamiento puruhá puede ser interpretado como una defensa del individuo que no quiere incurrir en muerte segura al añadir al calor o electricidad del rayo, el calor que genera la sal. Al parecer, un comportamiento similar existe en la región de El Cocuy, al Norte de Colombia.

En la provincia de Bolívar, Cantos (1965:259) señala que a 3 leguas de Tomabela "hay un pueblo con cierta cantidad de indios, donde hay una salinas que se usan y tienen sus granjerías los indios de Tomabela". Pomeroy (1986:11) ha descrito en la zona tres sitios de sal, el más grande, Cachipamba, o llanura de sal, utilizada para el refinamiento; Casahuayco, a $200 \mathrm{~m}$. del anterior, abandonado en 1970; y Minas o Pucacachi, a 1 km. al Oeste de Cachipamba, conocido por la sal roja que producía. Hoy se conoce bastante bien sobre los procedimientos de explotación (Pomeroy, 1986; Espinoza Soriano, 1988); pero muy poco del desarrollo de la industria de la sal. Aparentemente, los tomabelas tenían derecho consuetudinario sobre los manantiales (Cando, apodo de algunos caciques chimbos, significa manantial) y los controlaron solos por algún tiempo. Sin embargo, Salomon (1980:288), menciona que en un momento dado las salinas se convirtieron en "una isla multiétnica arquetípica". Se sabe además, que los tomabelas enviaban 
mercaderes a la provincia del Guayas con taleguillas de sal para trocar con oro, algodón, ají y pescado (Carranza, en Pomeroy 1986:27). Pero hacia 1754, las cosas habían cambiado: la sal ya no va de Tomabela a la Costa, sino al revés y a cargo de los mestizos. Montúfar y Fraso (1994:334) reporta que los mestizos de la zona conducían las 1500 mulas de la zona a la bodega de Babahoyo, cargadas de paños y comestibles, regresando con vinos, cacao, peces, y sal de Guayaquil. Hacia 1580, en la doctrina de Francisco de la Carrera, en la comarca de Chimbo, los caciques de San Llorente de Guamarica pagaban de tributo anual 6 cargas de sal, y los caciques de San Rafael de Cumbibamba dos cargas (Cantos, 1992:302). Igualmente, en 1605, los indios de Achambo entregaban a la iglesia en calidad de camarico, 12 cargas de sal, entre otras cosas (Anónimo, 1994:67).

En la Sierra meridional del Ecuador, el aprovisionamiento de la sal estaba bastante asegurado, ya sea por importación de la sal marina, o por obtención de fuentes locales, generalmente salitrales. En los documentos históricos se ve claramente que los centros urbanos grandes y sus pueblos más cercanos, donde la población blanco-mestiza era predominante, se importaba la sal marina, mientras los pueblos indígenas optaban por la explotación y consumo de sus salitrales.

En Cuenca (Pablos, 1965:269), la gente se abastecía de sal de la isla Puná, ya sea por el Puerto de Bola (en la costa de la Provincia del Guayas) o por el puerto de Yaguachi (en Guayaquil). No se sabe con precisión en donde estaba el Puerto de Bola, pero estimo que se hallaba en las inmediaciones de la desembocadura del rio Naranjal en el Golfo de Guayaquil. El camino a Cuenca fue siempre pésimo. Pablos (1965:269) señala que el abastecimiento de pescado marino y los bastimentos y ropa de Castilla eran muy caros en Cuenca colonial, "por ser el punto de Bola fragoso y mal camino, por no estar bien abierto". Los indios molleturos, que servían de arrieros, morían frecuentemente en la travesía; no era difícil que un viajero encontrara en su recorrido 5 o más cadáveres abandonados en la vía, como lo pudo constatar Requena (1982:42). Aún así, en 1754, la exportación de sal a Cuenca, desde Naranjal, alcanzaba a 1000 fanegas anuales (Montúfar y Fraso 1994:336).

Se conoce que Paute también prefería la sal marina de Puná (Pereira 1965: 273). La región de Azogues tenía abundante sal pero proveniente de salitrales, por ende poco apetecida por la población que, en la colonia temprana, prefería más bien abastecerse de la sal marina llegada a Cuenca (Gallegos, 1965:278). Por otro lado, al hablar del pueblo de Paccha, muy cercano a Cuenca, Fr. Domingo de los Ángeles (1965:270) señala que, antes de la conquista española, los cañaris "tenían guerras con los xibaros por les quitar las mujeres, y con los zamoranos sobre y en razón de defender las salinas". Los zamoranos son, sin duda, jíbaros de las estribaciones orientales de la provincia de Loja que a lo mejor ocupaban también la zona de Gualaquiza, donde se encuentra el rio Salado. Esta parece ser la fuente de la disputa con los Shuar, con una aclaración importante que se infiere del texto de de los Ángeles: era una "salina" explotada por los cañaris, y por tanto defendida de los ataques o de las pretensiones de apropiación por parte de los shuar. La fuente se encuentra además cerca del valle del rio Cuyes donde se han encontrado una serie de sitios fortificados o de mampostería de piedra, construidos al parecer por los Cañaris para defender un pequeño valle selvático del que se habían apropiado. En todo caso, el rio Salado reaparece en el siglo XX explotado por los colonos mestizos.

En la doctrina de Pacaybamba, al Sur de Cuenca, los indios explotaban unas salinas ubicadas “en sus sierras" (Arias Dávila, 1965:280) que bien puede ser el Nudo de Portete, o la cordillera de Mollepungo de los Andes Occidentales. Se desconoce si el pueblo de Cañaribamba utilizaba la misma fuente, ya que Pacaypamba no se encuentra muy lejos. En todo caso, el cronista señala que los naturales de Cañaribamba "hacían sal en ciertos tiempos del año" en un lugar distante cuatro leguas, aunque normalmente se aprovisionaban de sal marina en el Puerto de Machala (Gómez et al., 1965:285, Newson, 1995:51-52).

Por último, al referirnos a la ciudad de Loja, Salinas Loyola (1965a:293) comenta en la jurisdicción de la misma "no hay salinas, aunque hay algunas fuentecillas de agua salada de que se aprovechan los naturales: cociéndola sacan alguna sal para su sustento”. Cerca de Saraguro, 
Muñoz (1949:272) menciona el sitio El Salado, manantial de agua rico en cloruro de sodio que, a mediados del siglo pasado, era trabajado por habitantes locales para obtener sal. De ordinario, sin embargo, los habitantes de Loja, blancos y naturales, se aprovisionaban de sal marina del Puerto de Paita, donde "hay sierras de sal en piedra" (Id. 1965a:299). En efecto, lejos ya de la esfera de comercialización de la sal de la isla de Puná, las comunidades del Sur del país optaron por el aprovisionamiento desde las fuentes del Perú. A fines del siglo XVIII, Cicala (1994:562) señala la existencia y explotación de la "piedra de sal" en grandes extensiones costeras de los valles de Piura. Justamente los "ladrillitos de sal en piedra", panes de sal en forma de lajas de 10-12 libras, eran constantemente traficados con quiteños y panameños.

\section{La sal de la Amazonía}

En la amazonia ecuatoriana, el panorama de la sal es menos rico por carecer de fuentes naturales de importancia. A veces recurriendo a fuentes serranas y otras a fuentes selváticas muy lejanas, los indios del Oriente ecuatoriano, participaron en una esfera de trueque controlado básicamente por misioneros y comerciantes mestizos.

Los Quijos habitaban las estribaciones orientales de la cordillera, y en su territorio se fundaron las ciudades de españolas de Baeza, Ávila y Archidona. Los quijos prehispánicos han sido relacionados con la llamada fase Cosanga (700 a.C.-1200 d.C.), que ha dejado numerosos vestigios de construcciones "megalíticas" (Porras, 1975). Hay documentación histórica que reporta las incursiones en su territorio de los tres últimos Incas, antes de las numerosas expediciones españolas que culminaron con el establecimiento de la Gobernación de Quijos. Toribio de Ortiguera (en Porras, 1974:22) indica que, en la entrada de Huayna-Cápac, el inca trató con muchos regalos de obtener información sobre minas de oro; pero que los Quijos cedieron solamente ante el regalo de hachas de cortar y sal, "la cual tuvieron en mucho y por ella daban gran cantidad de oro a cargas". En la colonia temprana (ca. 1541), el P. Antonio Borja (1965:248) señala que los Quijos acudían a Chapi, pueblo de la jurisdicción de Pimampiro, trayendo muchachos y muchachas para trueque con mantas, sal, y perros. Efectivamente, los quijos carecían de fuentes de sal, aunque, al decir de Diego Hortegón (1989:261) obtenían "una que hazen unas yerbas con mucha pesadumbre y es amarga". Sin embargo, los quijos eran dedicados al comercio, que se lo realizaba, semanalmente, en lugares ad-hoc por todo su territorio. Según Hortegón (1989:260), el mercado se llamaba "gato" (una degeneración, sin duda, de "katu", el término quichua de mercado) donde se realizaban trueques de ropa, joyas de oro, comida y "otras cosas de la tierra", a la que se debe añadir para tiempos prehispánicos el comercio de esclavos.

Sabemos, por el episodio de Huayna-Cápac, que los Quijos conocían y apreciaban la sal en tiempos precolombinos y es probable que el aprovisionamiento del mineral se hiciera desde las fuentes serranas, las más cercanas a su territorio. Lamentablemente, la información respecto al comercio de los Quijos es prácticamente nula hasta la llegada de los jesuitas en su territorio y el establecimiento del curato de Archidona en 1660. Establecida Archidona, como punto de descanso de los jesuitas que entraban o salían de las misiones de Maynas, pronto pasó a cuartel general de la evangelización de los pueblos del Alto Napo. Los quijos por supuesto se adhirieron a la empresa jesuítica, ya como cargueros por las montañas, ya como remeros en los viajes a Maynas, lo que facilitó enormemente su actividad predilecta, el comercio. No era extraño encontrarlos residiendo en las misiones de Maynas, como es el caso de algunos quijos de Borja que acompañaron, entre 1750 y 1767, al P. Manuel Uriarte (1986:344) en sus misiones de Omaguas y Santa Bárbara. Un siglo después (1853), Herndon y Gibbon (1991, 1: 284) también señalan que han conocido en las misiones del Guallaga a muchos habitantes del Obispado de Quito. 
Dos ítems de intercambio llegaron a ser casi monopolio de los quijos en el comercio del Alto Napo, el curare de los Ticunas y Pebas, y la sal del Guallaga. Al principio los obtenían de los comerciantes Omaguas que remontaban el rio Napo, pero luego operarían independientemente. El curare era tan valorado por los quijos que exigían a los misioneros el pago en esta especie por su mano de obra (Oberem, 1980-205). A mediados del siglo XIX, en la república temprana, los quijos seguían manteniendo el control de esta substancia (Villavicencio, 1984:388).

La sal adquirían por medio de los misioneros y los comerciantes del Amazonas; pero al ser expulsados los jesuitas de América (1767), los quijos optaron por realizar viajes directos a las fuentes de sal. No eran los únicos, por cierto. Hay noticias de que, en 1770, los indios del Sureste de Colombia (i.e. Putumayo y Caquetá) también hacían viajes al Cerro de la Sal, por el lado de Yurimaguas. En efecto, Zawadzky (1947:155), al hablar del itinerario del misionero franciscano Fr. Bonifacio del Castillo, desde el pueblo de San Joaquín del río Putumayo hasta el mencionado Cerro, anota, solo en viaje de ida, un derrotero de 41 días.

Era sin duda una empresa de gran aliento, ya que los quijos comerciantes tenían que navegar el río Napo, aguas abajo, hasta su desembocadura en el Amazonas, luego remontar este río hasta la desembocadura del Guallaga, y continuar por él hasta Chasuta, en el curso medio de este río. En 1853, las colinas de sal se llamaban Callana Yacu que abastecían a la gente de dicho pueblo como a los indios del Ucayali y del Marañon (Herndon y Gibbon, 1991, 1: 232). Allí los quijos extraían la sal por el lapso de un mes, y regresaban en viaje relajado hasta la desembocadura del Napo, que luego había que remontar perezosamente, tanto por la corriente adversa, como por la pesada carga que llevaban. En suma, un viaje de cinco meses, desde julio hasta noviembre. Para dar una idea de las dificultades de la jornada, me permito citar in extenso el reporte que diera Simson de su viaje en 1874-75:

\footnotetext{
"Remar aguas abajo es una operación relativamente fácil; pero remontar las fuertes correntadas del Marañón y del Huallaga, cortar los bloques de sal en roca sin los implementos adecuados, y luego volver a remontar el Napo con las canoas tan cargadas, hacen de ello un trabajo que sólo los indios pueden soportar. Desde las más tempranas horas de la mañana hasta que oscurece, dos tres y cuatro de estos hombres, según el tamaño de la canoa, permanecen en la popa asidos de las pértigas, contrayendo toda su musculatura para conducir la barca, tan pesadamente cargada, rodeando los bancos en que sus palancas tocan el fondo, ejercicio que solo se cambia en cuanto se encuentra con una orilla escarpada, en que la corriente es demasiado fuerte para vencerla y en donde tienen que soltar las pértigas y manejar los remos con gran vigor hasta llegar al otro lado del ancho río, en el que vuelven a hacer uso de las palancas. Estos cruces son, con frecuencia, muy fatigosos, en especial en el Marañón, o en donde el canal es muy amplio, pues que los remeros no se atreven ni a tomar aliento, sino que tienen que remar con desesperación, solo para ver, a menudo, arrastrada por la corriente su tan pesada embarcación hacia atrás, tanto espacio como el que habían logrado adelantarla en medio día de muy ardua labor ... Durante estas jornadas, las manos y los pies se les cubren de una piel córnea de extraordinario espesor, tal como no le he visto en ninguna parte, y que a veces se les raja en profundas grietas, por el excesivo esfuerzo que hacen con los miembros y les ocasionan tortura y sufrimientos indecibles, a pesar de lo cual tienen que continuar en su labor..." (Simson, 1993:156-57).
}

Todo ello por un pago miserable: 30 o 35 varas de lienzo común para cada hombre, cuando la jornada corría a cuenta de un misionero o un comerciante (Simson, 1993:158). Cuando los quijos viajaban por cuenta propia, su estrategia consistía en adquirir comida a lo largo de los ríos, dando en trueque lienzo, espejos, collares, alfileres, y otras bagatelas. Ítems de mayor valor como hachas, machetes y telas eran utilizados solamente para el intercambio de curare y sal (Villavicencio, 1984:388; Oberem, 1980:205).

La expulsión de los jesuitas debilitó la red comercial de los quijos, y acaso forzó a la población a recurrir nuevamente a sus proveedores serranos. En 1799, Hernández Bello describe la mísera situación económica del territorio quijo que, obviamente, atribuye sólo a la desidia de los indios. 
El único comercio que menciona en la época es el realizado con los indios de la Tola, Ytulcachi, Tablón, Pintag y Alangasí, sus vecinos más próximos al otro lado de la cordillera, que cruzaban la Sierra de Guamaní, con algunas varas de tocuyo, pan, queso, sal y legumbres para hacer trueque por los afamados pilches y las calabazas de "diferente figura y tamaños" que producían los quijos (Hernández Bello, 1919:261).

No queda seguro si el retorno al comercio serrano es producto de una situación socioeconómica deteriorada, o simple reflejo de una escasez documental. Sesenta años después de Hernández Bello, el geógrafo Villavicencio (1984:387) señala que el comercio de los quijos se reduce a oro y pita (fibra trabajada del Agave sp.), mates o pilches, cera de abeja y copal, y vainilla, "todo en tan pequeña cantidad que apenas forma un miserable comercio". Sin embargo, los quijos de la selva más baja continúan navegando por los ríos del Alto Amazonas, buscando, como en los viejos tiempos, el curare y la sal del Guallaga. No por mucho tiempo, al parecer, porque los viejos problemas limítrofes de Ecuador y Perú, en una frontera difusa como era en ese tiempo la amazónica, volvieron dificultosa la navegación de los ríos del Alto Amazonas. En la década de 1840, comenzaron las "correrías" de moyobambinos, brasileros y peruanos que, en busca de zarzaparrilla, remontaban el Curaray y el Napo, atacando a menudo a los indios locales ecuatorianos. En 1850, la Dirección General de Oriente del Ecuador tuvo que expedir pasaportes para los quijos que viajaban al Guallaga (Villavicencio, 1860:36) y tenían que pasar por Iquitos, el nuevo puerto peruano, "caserío insignificante en 1860, y ya en 1875 población de 4000 habitantes (Valverde, 1919:138). Controles más rígidos se presentaron hacia 1890, con el establecimiento de colonos peruanos e inclusive un destacamento militar y autoridades civiles en Iquitos. En el primer tercio del siglo XX, Alomía (1936:307ss) reporta el hostigamiento a que eran sujetos los indios del Napo que remontaban el Guallaga. Sus canoas eran abordadas "diez o doce veces" en el trayecto, y los indios sometidos a vejámenes y a veces obligados a trabajar en las chacras peruanas por varios días, para permitirles continuar su jornada. El conflicto limítrofe de Ecuador y Perú habría pues cerrado el comercio de la sal.

En este punto cabe acaso una acotación poco elaborada de Villavicencio (1984:388), pero muy clarificadora de la situación. El autor divide a los quijos en dos grupos: los viajeros al Marañón y los viajeros a la Sierra. Los primeros están constituidos por los pueblos de Archidona, Ávila, Loreto y Concepción, los más avisados y emprendedores comerciantes de larga distancia. Los segundos serían los de los pueblos de Papallacta, Hatun-quijos, Baeza, Quijos, más cercanos a la cordillera, comerciantes de recursos limitados con los pueblos más cercanos del otro lado, con escala más lejana en Quito. En este contexto, se podría proponer para el territorio quijo una situación de comercio generalizado. Los "pobres" del Oeste (ni tan pobres porque también producían oro), que comerciaban directamente con la Sierra; y los más afluyentes del Este que se aventuraban por el ancho mundo del Alto Amazonas. Y sabemos que por ambas vías de comercio circulaba la sal de los cerros.

Cuanto de este panorama puede ser extrapolado al período precolombino, es difícil de evaluar. Si la información documental parece dar a los Quijos del Este la preeminencia en el comercio durante la colonia, el registro arqueológico, en cambio, la daría a los Quijos del Oeste. La cultura Cosanga fue sin duda un importante señorío que construyó caminos, plataformas, terrazas de cultivo y recintos con piedras lajas, a veces de enormes proporciones, además de una industria de utensilios líticos, y cerámica caracterizada por su invariable desgrasante de mica. Curiosamente, innumerables vasijas cosangas han aparecido en sitios serranos (donde constituyen el llamado estilo Panzaleo), cuya naturaleza de ítems de intercambio ha quedado bastante bien dilucidada (Bray, 1995). La “difusión” hacia el Este de vasijas cosangas es mucho más reducida. El punto más lejano es por el momento el sitio Aceipa-Palmeras (ca. $100 \mathrm{Km}$. al Este de Shushufindi), donde Ochoa (2002:13) reporta el hallazgo de cerámica fina con desgrasante de mica característica de esta cultura, aparentemente en asociación con cerámica de la fase Napo.

De los demás pueblos de la Amazonía ecuatoriana, la información disponible es muy escasa. En su descripción de 1784 de la provincia de Maynas, Echeverría y de Aguilar y Saldaña señalan 
que las antiguas tribus de simigayes, andoas y canelos que, a la sazón conformaban el pueblo de Santo Tomás de Andoas, se aprovisionaban de sal en minas existentes en el río Guallaga, en viajes anuales alrededor de agosto, en los que participaban todos los lugareños catequizados.

\begin{abstract}
"Desde este pueblo hasta el último de la Provincia, los naturales de ellas hacen su provisión de la sal que necesitan para comer en el año, de los cerros de la sal, situados a las riberas del río Guallaga, en sus cabeceras, donde se ve no sin admiración una mina o criadero de la sal más pura, limpia y cristalina, que cortan y acopian en sus canoas cuanta necesitan para sí y sus misioneros durante todo el año" (Echeverría, y de Aguilar y Saldaña 1895:348)
\end{abstract}

De los záparos (hoy llamados zápara), Osculati (1929,1:242; 2:53) reporta que generalmente no usaban la sal, sino la ceniza de hierbas aciduladas mezclada con sus alimentos; sin embargo, a veces la obtenían de los blancos intercambiándola con muchachos indios capturados en sus correrías.

Los shuar poseen algunas de fuentes de sal muy poco conocidas. Vacas Galindo (1903,3: 417) reporta en el rio Maembaimi, al Norte de Macas, un grupo de varias casas de jibaros que explotan un afloramiento de sal: "En sus inmediaciones, los Macabeos [habitantes antiguos de Macas] y los Jivaros extraen sal de unas pequeñas vertientes de aguas salinas, por lo cual aquellos llaman a ese lugar La Sal, y los Jivaros Hue Nunga”. Igualmente, señala en la orilla izquierda del río Upano, un afloramiento de sal en Mayahiko, atendido por un grupo shuar de 76 individuos: "Alli han ido varias familias para elaborar la excelente sal de Mayahiko, y comer el abundante pescado que alli se cría en el Upano" (Vacas Galindo (1903,3: 416). Cabe aquí señalar un error geográfico en que incurre Vacas Galindo por el desconocimiento, a fines del siglo XIX, del lugar de la desembocadura del Upano. La fuente de sal de "Mayalico", como se la conoce ahora, está en el río homónimo a muy poca distancia de la desembocadura de éste en el río Santiago. Ledergerber-Crespo (1995:363), que realizó hace algunos años un reconocimiento arqueológico en la zona, indica que se trata de dos vertientes de agua salada, aparentemente todavía en uso por parte de los shuar.

Harner (1973:128) también menciona dos fuentes tipo vertiente, en las inmediaciones de la Sierra de Cutucú, una en el Alto Mangosiza y otra en el río Yaupi. Finalmente, a comienzos del siglo XX, J.S. (1926) indica que en Gualaquiza "en estos últimos años se ha conseguido excelente sal, mediante la ebullición de las aguas del vecino río Salado, que sirve de abrevadero a los animales". De paso, esta es la única referencia en la que se menciona un procedimiento explícito de explotación. Y dado que todas las fuentes del territorio shuar son vertientes, habrá que asumir que la ebullición era el procedimiento estándar de obtención de sal. Sin embargo, se desconoce el volumen de producción y de intercambio. De hecho, se conoce que en la colonia temprana, los "indios de Macas" pagaban sus tributos sólo en oro o en tabaco (Villavicencio 1860:43). Así mismo, la obra de Brito (1938), pródiga en información sobre etnografía y recursos naturales del territorio shuar, entre 1888 y 1938, menciona solamente los numerosos lavaderos de oro locales, ignorando completamente la sal. En este contexto, habría que repensar la información de Vacas Galindo sobre las numerosas familias que trabajaban en las minas de sal del Upano. Considerando que los datos mencionados provienen de una exposición sobre el problema limítrofe entre Ecuador y Perú, en la que se defiende el principio del uti possidetis, no sería extraño que el autor haya caído en una pequeña "exageración patriótica" para demostrar que los territorios en discusión estaban realmente ocupados y explotados por ecuatorianos.

El único autor que menciona intercambio de sal es Harner (1973:29, 128). En un pasaje menciona a los macabeos obteniendo sal y cerdos de los shuar, y en otro a los achuar prefiriendo la sal shuar de Mangosiza y Yaupi, a la sal "inferior" (?) que podían obtenerla del alto Marañón (Huallaga?). Un último dato de equivalencias comerciales: Harner (1973:130) consigna una olla de sal como equivalente a una cerbatana, o a un pilche de curare achuara. Nada espectacular, entonces, como para propugnar a la sal como importante renglón de la economía de los shuar. 
Según Karsten (1919:334), en la mitología, los Shuar recibieron la sal de un jíbaro llamado Whui, quien la fabricaba secretamente haciendo hervir su orina en una olla. En otra versión del mito, sin embargo, Whui, en busca de un sitio donde asentarse definitivamente, acertó a pasar por el punto donde el río Curi-curi se une con el Mangosisa, donde descubrió un pozo de agua salada. Karsten señala que, en la época de su permanencia con los shuar, los jíbaros del Upano, del Morona y el Pastaza, acudían al lugar para sacar la sal, la misma que la obtenían cocinando el agua salada.

\section{La sal, interfase entre civilización y salvajismo}

En la vida humana, la sal es un elemento esencial para el organismo. Romanos y griegos la consideraban como "regalo divino", y el "más noble de los alimentos". Todos los poderosos han controlado su explotación y consumo. ¿Qué sería de la Iglesia Católica y de nuestro folklore sin el simbolismo de la sal? Entre estos y otros comentarios, Toussaint-Samat (1993:465) señala que la sal "puede no haber hecho historia, pero ha influido grandemente en el curso de la misma".

Curiosamente, y en plena era del "progreso", cuando el valor y alcance de los avances tecnológicos y los descubrimientos eran medidos cuidadosamente, la sal ha estado y está ausente del debate. A fines del siglo XIX, nadie como Morgan (1966) para darnos una evaluación de los hitos que marcaron el paso de la humanidad desde el salvajismo a la civilización. Pues bien, el antropólogo estadounidense nunca menciona el descubrimiento de la sal ni su uso como logros significativos de la humanidad.

En cambio, en el continente americano, la sal tiene otra dimensión. Es el marcador de la entrada en la civilización y la interfase entre naturaleza y cultura. Por cierto, no hay nada escrito sobre el tema en Ecuador; pero de las acciones y discursos de los involucrados en la explotación y el comercio de la sal se pueden encontrar interesantes connotaciones sociales. En este contexto, es interesante que el vagabundo Whui de la mitología Shuar se haya asentado definitivamente sólo cuando encontró un pozo de sal. Por otro lado, a mediados del siglo XVIII, el P. Magnin (1998:182), señalaba el carácter casi "urbano" del uso de la sal que "fuera de los pueblos no se usa y a veces dentro de ellos les falta", refiriéndose por "pueblos", generalmente a los centros misionales, el albergue de los indios civilizados.

Simson (1993:151) establece más claramente esta distinción: "Para evitar confusiones, mientras hable de la Provincia del Oriente y para usar términos apropiados, llamaré Infieles o Aucas cuando me refiera a las tribus que no comen sal y que no están catequizadas; y cuando hable de Indios se entenderá a los que hablan quichua y son gentes semi-cristianizadas que formaban parte un tiempo del gran imperio de los Incas".

La tradición oral de los Napo-runas, como llama Muratorio (1987) a nuestros Quijos, tiene una interesante historia del "callari tiempo" (el tiempo histórico y mítico), cuando estos indios vivían en muntuns (grupos) que vivían peleando entre sí: "Uno de esos muntuns decidió aceptar el bautismo y comer sal y así convertirse en "Runas"; y un segundo muntun que se negó a comer sal se convirtió en "Aucas" y se escondió en el monte (Muratorio 1987:55)". En Ecuador, el término Auca es usado, peyorativamente, para los indios más salvajes, siendo estos por antonomasia los Huaorani, que han protagonizado varios episodios sangrientos de matanzas en tiempos contemporáneos. Antiguamente, los indios amazónicos lo aplicaban por igual a todos sus semejantes no civilizados, aun a los de otras etnias, en cierto modo como los antiguos griegos aplicaron el término bárbaro.

Por otro lado, Echeverría, y de Aguilar y Saldaña (1895:348) reportan taxativamente que los indios infieles de Andoas eran excluidos de las expediciones en busca de la sal, en razón de que no la usaban. Si bien esta actitud parece razonable, no deja de tener una connotación de discriminación social, que privaba al salvaje del jolgorio que envolvía estas expediciones. Porque las jornadas de la sal eran todo un acontecimiento, en el que los expedicionarios adquirían 
estatura de héroes. Osculati (1929,2:7) señala, en su viaje de 1847, el apego que tenían los quijos por las largas navegaciones por el Napo; el título de "boga" era de gran honor para ellos que, a su regreso, podían acceder con más facilidad a los cargos de "justicias" o "caciques".

En su viaje de 1874-75, Simson (1993:159) indica que, a la partida y a la llegada de los expedicionarios, se celebraban grandes fiestas con abundante bebida de chicha. La costumbre dictaba que el inicio y la finalización de la jornada fueran anunciados con toques de bocina, hechos por los mismos expedicionarios:

"Si comenzasen o completasen el viaje sin tocar la bobona, se consideraría a los viajeros como de la más escasa significación y, por decir lo menos, pasarían entre sus amigos como ingenuos aprendices, destituidos de los más nobles atributos de los grandes viajeros" (Simson 1993:159).

Realmente cualquier cosa podía pasarle al viajero de la sal, menos llegar sin ser anunciado por la bobona. ¿Puede imaginarse el lector una selva soleada, el río manso lamiendo las orillas, y el bocinazo imprevisto que rompe el silencio, y la gente que sale a ver que es, y la canoa de la sal que aparece en el recodo del río, y los hombres que empiezan a remar vigorosamente como cuando salieron del Huallaga, y el bocinero erguido en la proa y el sonido de su bocina retumbando en el aire, y los gritos y la algarabía, y las canoas pequeñas que salen a recibirlos, y el desembarco, la admiración por sus héroes, y las largas tertulias para oír sus hazañas repetidas ad infinitum?... ¿Y, por otro lado, el infiel oculto entre las matas, mirando a hurtadillas, y ponderando la necesidad de civilizarse para el también disfrutar y ser protagonista de los beneficios sociales que le brindaría el mundo de la sal?.

\section{Bibliografía}

Alomía, Antonio. 1936, La defensa del Oriente ecuatoriano. Quito, Talleres Gráficos Nacionales.

Albornoz, Cristóbal de. 1989, Instrucción para descubrir todas las guacas del Pirú y sus camayos y haziendas. En Fábulas y mitos de los Incas, Madrid, Henrique Urbano y Pierre Duviols, eds., Historia 16, pp. 161-198.

Andrews, Anthony P. 1983, Maya salt production and trade. Tucson, The University of Arizona Press.

Angeles, Domingo de los (Fr.). 1965, San Francisco de Pacha y San Bartolomé de Arocxapa, vol. 2, En Relaciones Geográficas de Indias. Perú. Madrid, Marcos Jiménez de la Espada, ed. Biblioteca de Autores Españoles, pp. 270-271.

Anónimo. 1994, Descripción de los pueblos de la jurisdicción del Corregimiento de la Villa de Villar Don Pardo, de la provincia de los Purguayes [1605]. Vol.1, En Relaciones Histórico-Geográficas de la Audiencia de Quito (Siglos XVI-XIX), Pilar Ponce Leiva, ed. Quito, MARKA, Ediciones Abya-Yala, pp. 48-70.

Arias Dávila, Pedro. 1965, Pacaipamba o Leoquina. Vol. 2, En Relaciones Geográficas de Indias. Perú. Madrid, Marcos Jiménez de la Espada, ed. Biblioteca de Autores Españoles, pp. 278-281.

Biedma, Manuel, y otros. 1989, La conquista franciscana del Alto Ucayali. Monumenta Amazonica, vol. B5, Iquitos, IIAP-CETA.

Borja, Antonio (P.). 1965, Relación en suma de la Doctrina e Beneficio de Pimampiro y de las cosas notables que hay en ella. Vol. 2, En Relaciones Geográficas de Indias. Perú. Madrid, Marcos Jiménez de la Espada, ed. Biblioteca de Autores Españoles, pp. 248-253.

Bray, Tamara L. 1995, The Panzaleo puzzle: non-local pottery in Northern Highland Ecuador, Journal of Field Archaeology 22(2):137-1456.

Brito, Elias (S. S.). 1938, Misiones Salesianas del Oriente Ecuatoriano. Tomo 3 de La Apoteosis de San Juan Bosco en el Ecuador, Quito, Escuela Tipográfica Salesiana.

Caillavet, Chantal. 2000, La sal de Otavalo. Continuidades indígenas y rupturas coloniales. En Etnias del Norte. Etnohistoria e historia de Ecuador. Quito, Ediciones Abya-Yala, IFEA. 
Cantos, Miguel de. 1965, Relación para la Real Audiencia de los repartimientos y número de indios y encomenderos que hay en el Corregimiento de Chimbo [1581]. Vol. 2, En Relaciones Geográficas de Indias. Perú, Madrid, Marcos Jiménez de la Espada, ed. Biblioteca de Autores Españoles, pp. 254-259.

Cantos, Miguel de. 1992, Doctrina de Francisco de la Carrera por beneficio [1580]. Vol.1, En Relaciones HistóricoGeográficas de la Audiencia de Quito (Siglos XVI-XIX), Pilar Ponce Leiva, ed. MARKA, Ediciones AbyaYala, Quito, pp.297-303.

Carvalho-Neto, Paulo de. 2001, Diccionario del folklore ecuatoriano, Quito, Editorial Casa de la Cultura Ecuatoriana. Segunda edición.

Cicala, Mario, S. I. 1994, Descripción histórico-topográfica de la Provincia de Quito de la Compañía de Jesús [1771]. Quito, Biblioteca Ecuatoriana Aurelio Espinosa Pólit.

Cieza de León, Pedro. 2001, Descubrimiento y conquista del Perú. Madrid, Dastin.

Cobo, Bernabé. 1964, Historia del Nuevo Mundo, 2 vols., Madrid, Biblioteca de Autores Españoles.

Echeverri, Juan Alvaro. 2000, The first love of a young man. Salt and sexual education among the Uitoto Indians of Lowland Colombia. En The Anthropology of love and anger. The aesthetics of conviviality in native Amazonia, Londres, Joanna Overing y Alan Passes, eds. Routledge, p. 33-45.

Echeverría Mariano; y Francisco de Aguilar y Saldaña. 1895, Relación geográfica de la Provincia de Maynas (fragmento del original de 1784). Tomo I, En Antología de Prosistas Ecuatorianos, Quito, Pablo Herrera, ed. Imprenta del Gobierno, pp. 346-364.

Espinoza Soriano, Waldemar. 1988, La etnia chimbo, al oeste de Riobamba: el testimonio de la etnohistoria, Guayaquil, Museos del Banco Central del Ecuador.

Estrella, Eduardo. 1977, Medicina aborigen ecuatoriana. La práctica médica aborigen en la Sierra ecuatoriana, Quito, Editorial Epoca.

Ewald, Ursula. 1985, The Mexican salt industry, 1560-1980. A study in change. Stuttgart, Gustav Fischer Verlag.

Gallegos, Gaspar de (Fr.). 1965, Sant Francisco Pueleusi del Azogue. vol. 2, En Relaciones Geográficas de Indias. Perú, Madrid, Marcos Jiménez de la Espada, ed. Biblioteca de Autores Españoles, pp. 274-278.

Gómez, Juan; Juan Vélez Benavente; y Alvaro García de Balcázar. 1965, Cañaribamba, vol. 2, En Relaciones Geográficas de Indias. Perú, Madrid, Marcos Jiménez de la Espada, ed. Biblioteca de Autores Españoles, pp. 281-285.

Harner, Michael. 1973, The Jivaro, people of the sacred waterfalls, Garden City, Anchor Press.

Hernández Bello, Miguel. 1919, Descripción del Govierno de Quijos. Boletín de la Sociedad Ecuatoriana de Estudios Históricos Americanos 3(7-9):257-263.

Herndon, Wm. L.; y Lardner Gibbon. 1991, Exploración del valle del Amazonas, 2 vols. Quito, Monumenta Amazonica, Serie D3, IIAP-CETA, Abya-Yala, Iquitos.

Hortegón, Diego (Licenciado). 1989, Relación del estado en que se encuentra la Gobernación de Quijos y la Canela [1577]. En La Gobernación de Quijos (1559-1621), Iquitos, Monumenta Amazonica, Serie A1, IIAPCETA, pp. 257-271.

Hugh-Jones, Christine. 1979, From the milk river: spatial and temporal processes in Northwest Amazonia, Cambridge, Cambridge University Press.

J. S., 1926, El Valle de Gualaquiza. En Monografía del Azuay, Luis F. Mora, y Arquímedes Landázuri, eds., sin paginación, Cuenca, Tipografía de Burbano Hnos.

Jiménez de la Espada, Marcos, (ed.). 1965, Relaciones Geográficas de Indias. Perú, 2 vols., Madrid, Biblioteca de Autores Españoles.

Juan, Jorge; Antonio de Ulloa. 1748, Relación histórica del viaje a la América meridional, 3 vols., Madrid, Fundación Universitaria Española. Facsímil del original.

Lippi, Ronald D. 2004, Tropical Forest Archaeology in Western Pichincha, Ecuador, Belmont, CA, Wadsworth Thompson Learning.

Karsten, Rafael. 1919, Mitos de los indios Jíbaros (Shuará) del Oriente ecuatoriano. Boletín de la Sociedad Ecuatoriana de Estudios Históricos Americanos 2(6):325-339.

Ledergerber-Crespo. Paulina, 1995, Factores geográficos en la localización de sitios arqueológicos. El caso de Morona-Santiago, Ecuador. Un informe preliminar. En Cultura y medio ambiente en el área andina septentrional, Mercedes Guinea, Jean-François Bouchard, y Jorge Marcos, eds. Quito, Ediciones Abya-Yala, pp.343-375.

Magnin, Juan, S.I. 1998, Descripción de la Provincia y Misiones de Mainas en el Reino de Quito. Quito, Sociedad Ecuatoriana de Investigaciones Históricas y Geográficas. 
Molina, Cristóbal de. 1989, Relación de las fábulas y ritos de los Incas. En Fábulas y mitos de los Incas, Madrid, Henrique Urbano y Pierre Duviols, eds. Historia 16, pp. 47-134.

Montúfar y Fraso, Juan Pío. 1994, Razón sobre el estado y gobernación política y militar de las provincias, ciudades, villas y lugares que contiene la jurisdicción de la Real Audiencia de Quito [1754]. Vol. 2, En Relaciones Histórico-Geográficas de la Audiencia de Quito (Siglos XVI-XIX), Pilar Ponce Leiva, ed. Quito, MARKA, Ediciones Abya-Yala, pp. 323-352.

Morgan, Lewis Henry. 1969, Ancient Society. Meridian Books. Cleveland, The World Publishing Company.

Muñoz, José E. 1949, Aguas minerales del Ecuador y nociones de hidrología general, Quito, Talleres Gráficos Nacionales.

Muratorio, Blanca. 1987, Rucuyaya Alonso y la historia social y económica del Alto Napo. Quito, Ediciones Abya-Yala.

Newson, Linda. 1995, Life and death in Early Colonial Ecuador. Norman University of Oklahoma Press.

Oberem, Udo. 1980, Los Quijos. Historia de la transculturación de un grupo indígena en el Oriente Ecuatoriano. Colección Pendoneros, vol. 16, Otavalo, Instituto Otavaleño de Antropología.

Ochoa, Myriam. 2002, Informe de la prospección, rescate y monitoreo arqueológicos del campo Edén-Yuturi. Bloque 15, Provincia de Orellana. Quito, Informe al Instituto Nacional de Patrimonio Cultural.

Olivas Weston, Rosario. 2006, La cocina de los Incas. Costumbres gastronómicas y técnicas culinarias, Lima, Universidad de San Martín de Porres, Eascuela Profesional de Turismo y Hotelería.

Osculati, Gaetano. 1929, Esplorazioni nell'America equatoriale, dos vols. Milán, Edizioni Alpes.

Pablos, Hernando. 1965, Relación de la ciudad de Cuenca y toda su Provincia. vol. 2, En Relaciones Geográficas de Indias. Perú, Madrid, Marcos Jiménez de la Espada, ed. Biblioteca de Autores Españoles, pp. 265-270.

Palacios, Silvio; y Ena Zoffoli. 1991, Gloria y tragedia de la misiones guaraníes. Historia de las reducciones jesuíticas durante los siglos XVII y XVIII en el Río de La Plata. Bilbao, Ediciones Mensajero.

Patiño, Víctor Manuel. 1992, Historia de la cultura material en la América equinoccial, tomo 5, Tecnología, Bogotá, Instituto Caro y Cuervo.

Paz Maldonado, Juan de. 1965, Relación del pueblo de Sant Andrés de Xunxi. vol. 2, En Relaciones Geográficas de Indias. Perú, Madrid, Marcos Jiménez de la Espada ed. Biblioteca de Autores Españoles, pp. 261-264.

Paz Ponce de León, S. 1965 [1582], Relación y descripción de los pueblos del partido de Otavalo, vol. 2, En Relaciones Geográficas de Indias. Perú, Madrid, Marcos Jiménez de la Espada, ed. Biblioteca de Autores Españoles, pp. 233-242.

Pereira, Mor. De (Fr.). 1965, San Luis de Paute. vol. 2, En Relaciones Geográficas de Indias. Perú, Madrid, Marcos Jiménez de la Espada, ed. Biblioteca de Autores Españoles, pp. 271-274.

Pomeroy, Cheryl. 1986, La sal en las culturas andinas. Quito, Mundo Andino.

Ponce Leiva, Pilar, (ed.). 1992-94, Relaciones Histórico-Geográficas de la Audiencia de Quito (Siglos XVIXIX), 2 vols., Quito, MARKA, Ediciones Abya-Yala.

Porras, Pedro I. 1974, Historia y arqueología de la ciudad española de Baeza de los Quijos, siglo XVI. Quito, Pontificia Universidad Católica del Ecuador.

1975, Fase Cosanga. Quito, Ediciones de la Universidad Católica.

Prescott, William H., s.f. History of the Conquest of Mexico and History of the Conquest of Perú. New York, The Modern Library., Random House.

Requena, Francisco, 1982 [1774], Descripción histórica y geográfica de la provincia de Guayaquil, en el Virreinato de Santa Fe, para acompañar al mapa general de su distrito e inmediaciones, Historiografía y Bibliografía Americanistas, 26: 27-134.

Rydén, Stig. 1962, Salt trading in the Amazon Basin. Conclusions suggested by the distribution of Guarani terms of salt. Anthropos 57:644-659.

Salinas Loyola, Juan de. 1965a, Relación y descripción de la ciudad de Loxa. 1573. vol. 2, En Relaciones Geográficas de Indias. Perú, Madrid, Marcos Jiménez de la Espada, ed. Biblioteca de Autores Españoles, pp. 291-306.

1965b, La Cibdad de Sant Francisco de Quito. 1573. vol. 2, En Relaciones Geográficas de Indias. Perú, Madrid, Marcos Jiménez de la Espada, ed. Biblioteca de Autores Españoles, pp. 203-232.

Salomon, Frank. 1980, Los señores étnicos de Quito en la época de los incas. Otavalo, Instituto Otavaleño de Antropología.

Simson, Alfred. 1993, Viajes por la selvas del Ecuador y exploración del río Putumayo. Colección Tierra Incógnita, vol. 8. Quito, Ediciones Abya-Yala.

Toussaint-Samat, Maguelonne. 1993, A History of food. Cambridge, Blackwell. 
Uriarte, Manuel J. (S.I.). 1986, Diario de un misionero de Maynas. Iquitos, Monumenta Amazonica, Serie B2, IIAP-CETA.

Useche Losada, Mariano. 1989, Sistemas Extensos de Intercambio y fronteras interiores: reflexiones para una historia. En Lingüística, ecología, selvas tropicales, Villa de Leyva, Miguel A. Meléndez, Piedad Gómez Villa, Beatriz Alzate, Roberto Pineda, Miguelángel Roldán, eds. Memorias del V Congreso Nacional de Antropología, pp. 183-190.

Vacas Galindo, Enrique (Fr.). 1903, Exposición sobre los límites ecuatoriano-peruanos, Tomo 3. Quito, Escuela de Artes y Oficios.

Valdizán, Hermilio; y Angel Maldonado. 1985, La medicina popular peruana, 3 vols. Lima, Edición facsimilar de la original de 1922. Consejo Indio de Sud América.

Valverde, Miguel. 1919, Las anécdotas de mi vida. Tomo Primero. Grottaferrata, Tipografia Italo-orientale.

Valverde, Pedro de; y Juan Rodríguez. 1965, Relación de la Provincia de Quito y Distrito de su Hacienda, por los Oficiales de la Real Hacienda, 1573, vol. 2. En Relaciones Geográficas de Indias. Perú, Madrid, Marcos Jiménez de la Espada, ed. Biblioteca de Autores Españoles, pp. 169-182.

Varese Stefano. 1973, La sal de los cerros. Lima, Retablo de Papel Ediciones.

Villavicencio, Manuel. 1860, Apéndice a la Jeografía del Ecuador y defensa de los terrenos baldíos. Valparaíso, Imprenta y Librería del Mercurio, de S. Tornero.

1984, Geografía de la República del Ecuador. Edición facsimilar de la primera de 1858. Quito, Corporación Editora Nacional.

Wheat, Joe Ben. 1972, The Olsen-Chubbuck site. A Paleo-Indian bison kill. Memoirs of the Society for American Archaeology, $\mathrm{N}^{\mathrm{o}} 26$.

Wörrle, Bernhard. 1999, De la cocina a la brujería. La sal entre indígenas y mestizos en América Latina. Quito, Ediciones Abya-Yala.

Ytaliano, Hernando. 1965, Alausi, vol. 2. En Relaciones Geográficas de Indias. Perú, Madrid, Marcos Jiménez de la Espada, ed.. Biblioteca de Autores Españoles Pp.287-289.

Zawadzky C. Alfonso, 1947, Viajes misioneros del R. P. Fr. Fernando de Jesús Larrea, 1700-1773. Cali, Imprenta Bolivariana.

Zelaya, Juan Antonio, 1994, Estado de la provincia de Guayaquil [1765] Vol.2. En Relaciones HistóricoGeográficas de la Audiencia de Quito (Siglos XVI-XIX), Pilar Ponce Leiva, ed. Quito, MARKA, Ediciones Abya-Yala, pp. 361-368. 